\title{
Effect of core stability training on postural control, risk of falling, and function of the blind: A randomized controlled trial
}

Authors' Contribution: A Study Design

B Data Collection

C Statistical Analysis

D Data Interpretation

E Manuscript Preparation

F Literature Search

G Funds Collection

\author{
Mohammad Karimizadeh Ardakani ${ }^{1}$ ABCDEF, Mohammad Hamzeh Shalamzari ${ }^{2}$ ABCDEF, \\ Mohammad Hani Mansori² ABCDEF \\ ${ }^{1}$ Department of Health and Sport Medicine, \\ Faculty of Physical Education and Sport Sciences, University of Tehran, Tehran, Iran \\ ${ }^{2}$ Sport Injury and Corrective Exercise Student, Department of Health and Sport Medicine, \\ Faculty of Physical Education and Sport Sciences, University of Tehran, Tehran, Iran
}

\section{abstract}

Background: Visual impairments affect all motion aspects of individuals. Movement as the most important tool of physical education is an important factor to improve the health of people with disabilities. The present study aims to investigate the effect of six weeks of core stability training on postural control, risk of falling, and function of blind people.

Material and methods: Thirty-two blind males were randomly divided into two groups: the experimental and the control one. In order to evaluate the postural control, the Berg balance scale, the modified stork stand balance test, and the tandem walking test were used. To evaluate the risk of falling and function, the Timed Get up \& Go and Tinetti tests were employed, respectively. Data were analysed via MANOVA statistical analysis test at the significance level of 0.05 .

Results: Results showed that, after 6 weeks of core stability training, a significant increase was observed in postural control scores, function, and risk of falling in the experimental group compared to the control group and the pre-test condition $(\mathrm{P}<0.05)$.

Conclusions: Considering the importance of mobility, especially in people with visual disabilities, the use of core stability training is suggested as an effective method to improve efficiency of daily activity of these people.

Key words: postural control, blind people, core stability training, risk of falling, function.

\section{article details}

Article statistics: Word count: 4,034; Tables: 4; Figures: 2; References: 37

Received: October 2019; Accepted: May 2020; Published: September 2020

Full-text PDF: http://www.balticsportscience.com

Copyright ๑ Gdansk University of Physical Education and Sport, Poland

Indexation: Celdes, Clarivate Analytics Emerging Sources Citation Index (ESCI), CNKI Scholar (China National Knowledge Infrastructure), CNPIEC, De Gruyter - IBR (International Bibliography of Reviews of Scholarly Literature in the Humanities and Social Sciences), De Gruyter - IBZ (International Bibliography of Periodical Literature in the Humanities and Social Sciences), DOAJ, EBSCO - Central \& Eastern European Academic Source, EBSCO - SPORTDiscus, EBSCO Discovery Service, Google Scholar, Index Copernicus, J-Gate, Naviga (Softweco, Primo Central (ExLibris), ProQuest - Family Health, ProQuest - Health \& Medical Complete, ProQuest - Illustrata: Health Sciences, ProQuest - Nursing \& Allied Health Source, Summon (Serials Solutions/ProQuest, TDOne (TDNet), Ulrich's Periodicals Directory/ulrichsweb, WorldCat (OCLC)

Funding: This research has been done in the form of research project No. 30938/2 using research credits of Tehran University.

Conflict of interests: Corresponding author:

Open Access License:
Authors have declared that no competing interest exists.

Dr. Mohammad Karimizadeh Ardakani, Department of Health and Sport Medicine, Faculty of Physical Education and Sport Sciences, University of Tehran, No. 15th Alley, Amir Abad Street, Kargar Street, Tehran, Iran; tel.: +989104963054; e-mail address: m.karimizadeh@ut.ac.ir

This is an open access article distributed under the terms of the Creative Commons Attribution-Non-Commercial-NoDerivatives 4.0 International (https://creativecommons.org/licenses/by-nc-nd/4.0/), which permits use, distribution, and reproduction in any medium, provided the original work is properly cited, the use is non-commercial and is otherwise in compliance with the license. 


\section{INTRODUCTION}

Visual impairment is one of the most common functional impairments and causes of disability in adults, which affects daily mobility and activity [1]. Blindness and poor vision are considered two important health, economic and social issues in developed and developing countries [2]. According to the World Health Organization [3], out of the world population of 7.3 billion, 36 million people are blind, 217 million people suffer from moderate to severe visual impairment, and 188 million people suffer from moderate to low visual impairment. Although other senses provide valuable information, it is the sense of vision that rapidly provides the most reliable information about the environment and accounts for almost one-third of human brain processes [4].

Postural control is the intrinsic ability to create or restore the balance of an individual in any position or any motor activity [5]. Postural control is a complex task that involves predicted responses to keep person's balance via coordinated interaction of the somatosensory, vestibular, and visual systems. Studies have shown that vision plays a major role in postural control, and lack of vision in blind people leads to the impaired balance at both static and dynamic levels. The results of studies on balance of people with visual impairment or blindness show that visual impairment considerably affects the postural control process [6]. Functional movement is defined as the ability to create and maintain balance between mobility and stability along the kinetic chain while performing fundamental patterns with precision and efficiency [7]. The importance of balance has always been of interest to researchers for the prevention of falling. Hence, researchers are seeking to identify factors affecting the improvement of this important physical factor. Some researchers have examined the mechanical effects and function of the upper and lower extremities on balance [8]. Many training methods have been recently developed for core stability; not only for athletes [9], but also for women [10], the elderly [11], and other groups. Core stability training has been identified as very effective to strengthen muscles, increase flexibility, and to improve postural control [12] and balance function for professional athletes as well as healthy people of all ages and genders. Moreover, these trainings are widely used in planning training to increase function [13]. Experimental evidence from studies indicates that core muscle training has beneficial effects on balance control. Iacono et al. [14] showed that 4 weeks of core stability training improved the static and dynamic balance of soccer players. Core strength is an important prerequisite for several sports, such as track and field, mountain climbing, soccer, and daily activities, such as sitting, standing and walking in a standing position [13].

With regard to these findings, it seems that core stability training can have the potential to improve health factors (strength, flexibility), skill-related components (balance, coordination, speed), and fitness components in youth [15]. In recent years, core stability training has been widely used to improve function, reduce the risk of injury in athletes, increase physical fitness in individuals, and rehabilitate those with lower back pain [16]. Core stability training might lead to improved dynamic balance function and coordination between upper and lower extremities, reduced risk of injury, and decreased muscle incoordination. There are trainings that do not require specific tools and equipment, nor a certain place for such trainings; this benefit is very useful for the blind people given their disability. To the best of the authors' knowledge, by studying the literature review, no research has been conducted to examine the effect of core stability training on blind people. 
Therefore, the aim of this study was to investigate the effect of six weeks of core stability training on postural control, risk of falling, and function of blind people. Given the existing literature and background, we assume that the core stability training is capable of changing balance and functional deficits in the blind people.

\section{MATERIAL AND METHODS}

\section{RESEARCH DESIGN}

This study was a randomized controlled trial with pre-test and post-test design carried out on 32 blind university students aged 18-30 years old. Stratified randomization was applied, ensuring that experimental and control groups were balanced for the type and severity of blindness. Statistical population of this study consisted of male students with blindness in University of Tehran, among whom 32 men with congenital or acquired blindness were selected with respect to the inclusion criteria. In this study, the minimum sample size of 16 per group was considered with regard to earlier research using G-Power sample size estimate equation and taking into account test power of $80 \%$ and effect size of 0.8 [17].

\section{INDIVIDUALS}

With regard to the statistical population of blind people in University of Tehran, there were 52 volunteers in the research, from among whom 16 individuals were not qualified to enter the research given the inclusion criteria. Among the remaining 36 participants, two from each group were excluded for various reasons and, finally, 32 participants remained (Figure 1).

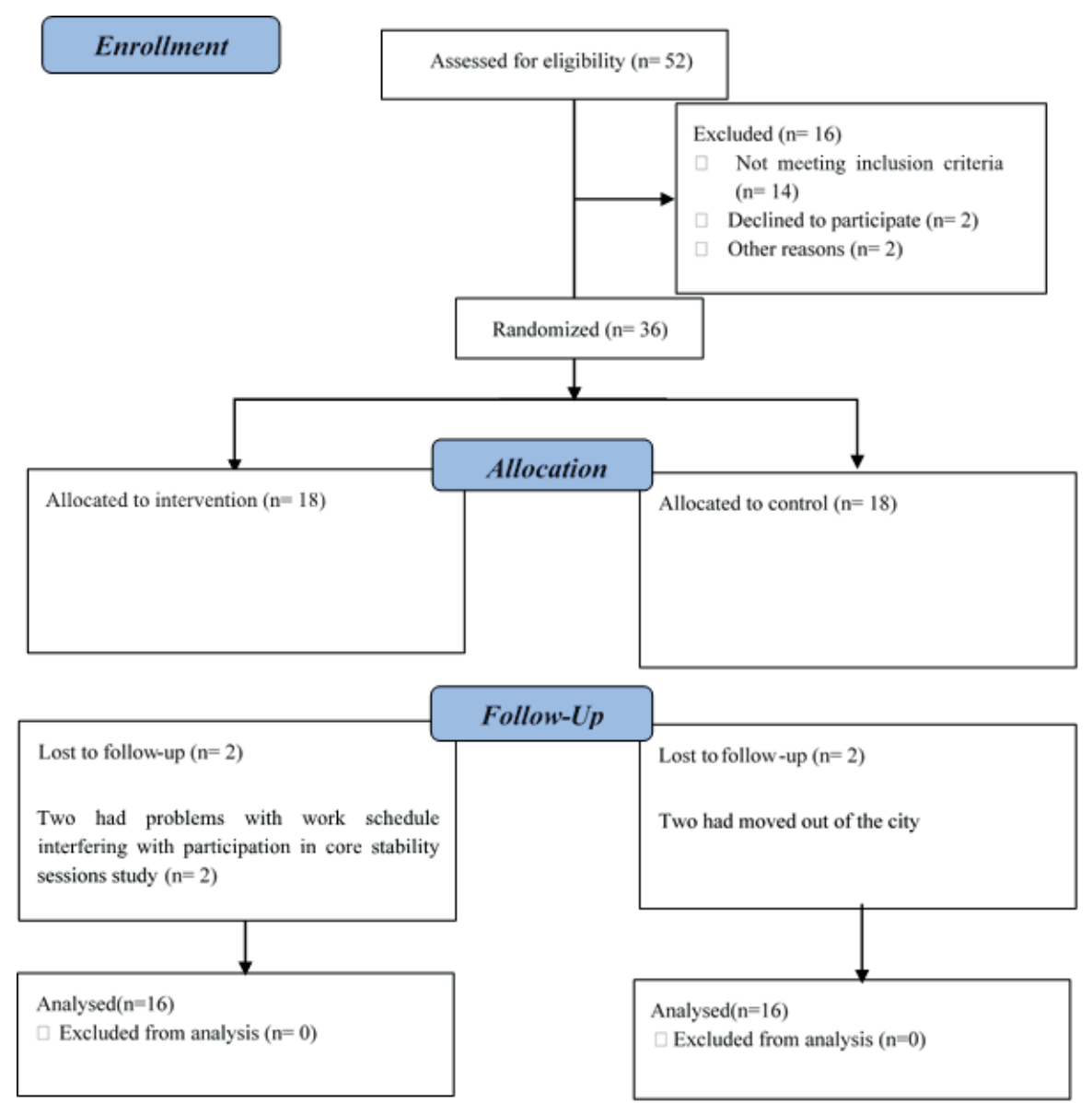

Fig. 1. CONSORT flow chart of participant enrollment, allocation, follow-up, and analysis 
The research sample was selected via convenience and purposeful sampling from among the students of the University of Tehran and divided into a control group ( $\mathrm{n}=16$, mean and standard deviation of age $22.50 \pm 2.80$ years old, weight $73.43 \pm 6.39 \mathrm{~kg}$, height $173.68 \pm 4.65 \mathrm{~cm})$ and an experimental group $(\mathrm{n}=16$, mean and standard deviation of age $23 \pm 3.03$ years old, weight $75.73 \pm 9.05 \mathrm{~kg}$, height $(174.62 \pm 4.99 \mathrm{~cm})$.

\section{RESEARCH AREA}

The inclusion criteria were as follows: being male, acquired or congenital blindness, severity of absolute or poor blindness based on the ICD classification (no perception of light and presenting distance visual acuity worse than 1/60 or $3 / 60$ equal to or better than light perception or $1 / 60$ respectively), capability of walking independently, lack of pain and injury in the waist and lower extremity, no surgery in lower extremity joints, lack of apparent musculoskeletal disorders in lower extremity [18], voluntary participation in research, and understanding the research instructions [19], lack of cardiovascular problems, diabetes, neuropathy, and no history of disease or medicine that affects the nervous system [20]. Exclusion criteria were as follows: any pain during training, no history of participation in competitions related to the sport in question, having another sensory disorder in addition to blindness, not giving consent to further research, personal problems, lack of cooperation with the researcher, and physical and movement problems of students; in accordance with the records, no one had physical problems and, thus, no one was excluded. The process and goals of the research were explained to all the participants prior to the study and they all signed the consent form that was approved by Faculty of Physical Education and Sport Sciences.

This research was derived from the research plan approved at University of Tehran (30938/2). It should be noted that the present research was approved by Ethics Committee of Institute of Sport Sciences, IR.SSRI.REC.1398.051.

\section{PROCEDURES}

Eligible individuals, given the inclusion and exclusion criteria, were contacted to participate in a session to be acquainted with the research process. During the session, the test instructions and a training plan were given to the participants. All the participants completed pre-tests a week prior to the intervention. Immediately after the training intervention by the experimental group that lasted for six weeks, post-tests were administered in a similar manner to the pre-tests in order to determine the effect of exercise. In order to perform the present study, the Berg balance scale, the modified stork stand balance test, and the tandem walking test were used for posture control, the TUG test was employed for risk of falling, and the Tinetti test was used to evaluate the function.

Berg balance scale: This scale, consisting of 14 items, objectively evaluates functional capabilities of posture and dynamic balance and involves daily activities such as sitting, standing and moving, to each of which a score of 0 to 4 is assigned based on the type of implementation. The scores range is 41-56 (lowest risk of falling), 21-40 (average risk of falling), and 0-20 (high risk of falling). A sum of these scores for 14 items for each individual predicts the risk of falling and loss of postural control [21]. The reliability of each section of Berg scale is $98 \%$, validity of each section is $99 \%$, and intra-class correlation coefficient of the scale is reported to be $96 \%$ [22]. 
Modified stork stand balance test: The present test was performed as follows: The participant stood with one foot on the flat surface and raised his free leg up to the ankle of the support leg; both hands were free beside the body (Fig. 2a). Once the participant laid his free foot on the ground, the time stopped. The maximum time the participant stood on his leg was considered as his record. The test was performed twice on both legs and the best time was registered as the record. The reliability of this test was reported to be 93\% [23].

Tandem walking test: Tandem walking test was used to measure the dynamic balance. By this test, the participant's capability of walking on a straight path in a way that toes of the back foot touch the heel of the front foot is evaluated. The test was performed as follows: The participant walked on a certain path with length of 15 steps and the maximum score was 15 (Fig. 2b). If the participant deviated from path before completing 15 steps, the test was stopped and the number of steps was recorded. The test was implemented twice, and the better score was recorded as the participant's record. The reliability of this test was 91\% [23].

TUG: This test was designed by Matthias in 1986 and had a scoring scale of 1-5. The timed get up \& go (TUG) test consists of sitting on a chair, standing, and walking up to 3 meters, coming back, and sitting on a chair again (Fig. 2c). The criterion for this test is the length of time that a person performs the motion manoeuvre from the moment of getting up from a chair to sitting down again, measured using a chronometer. The length of this test for young people is 5-7 seconds [24]. The validity and reliability of this test were reported to be very high [25].
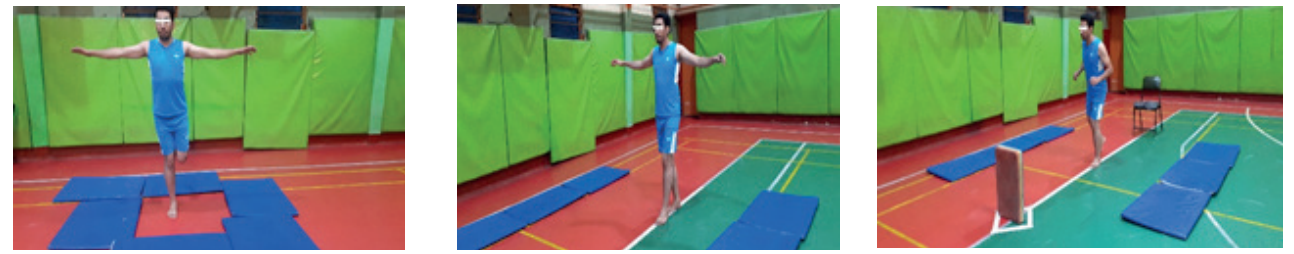

Fig. 2. a) Modified stork stand balance test, b) Tandem walking test, c) TUG test

Tinetti test: This test was developed by Tinetti in 1986 and consists of two parts. The first part involves examination of sitting, getting up, and standing, and the second part involves examination of gait. The first part consists of 9 motion manoeuvres, and each section is scored from zero to a maximum of two points. The second part involves examination of 7 components of gait. The time required for the test is 10 to 15 minutes. The best score is 16 for the balance and 12 for gait, and in total, the best score is 28 . A score below 19 indicates a high risk of falling. The validity and reliability of this scale have been examined in various studies and this test is moderately associated with the Timed Get up \& Go test [25]. All the tests were performed at Physical Education Laboratory, the University of Tehran.

Training intervention: After the pre-tests, the participants completed a 6-week training protocol. The core stability training protocol lasted for six weeks and was performed three times a week. The content of each training session lasted for almost 30 minutes, which began by a 5 min warm-up and ended by a 5 min cool-off for the experimental group. The training was presented based on core stability training proposed by Jeffrey and consisted of 3 levels [26]. The training began from level 1 including static contractions in a steady state, level 2 training including static contractions in an unstable environment, and finally, level 3 training including dynamic movements in an unstable environment (Table 1). 
The activity level of all the participants in the experimental and control groups was considered the same; hence, the control group was used to control the possible effect of daily training and activities on the balance of subjects. In the training, the body weight, medicine balls, therapeutic resistance bands, and Swiss balls were utilised. The number of sets and repetitions and retention times for each week were adjusted at three sets and 20 seconds of contraction for isometric contraction, and three sets and 20 repetitions for isotonic contraction [26]. The sample completed the training plan three times a week during regular planning. If the participants did not attend a specific training session, the training plan would be completed for them the next sessions. The core stability training plan lasted for almost 30 minutes for six weeks up to the total of 18 sessions. All the training sessions were supervised by the researchers and gym trainer from Men's Dormitory of University of Tehran.

Table 1. Core-Stability-Training Program

\begin{tabular}{|c|c|c|}
\hline Week & Exercise & Sets, Reps, Time \\
\hline \multirow{4}{*}{1} & Abdominal bracing, hollowing & \multirow{4}{*}{$\begin{array}{l}\text { All exercises were held for } \\
20 \text { s before returning to } \\
\text { starting position }\end{array}$} \\
\hline & Prone bridge & \\
\hline & Supine bridge & \\
\hline & Side bridge & \\
\hline \multirow{5}{*}{2} & Supine bent-knee raise & \multirow[t]{5}{*}{20 reps } \\
\hline & Quadruped alternate-arm leg raise & \\
\hline & Supine bridge exercise with alternate leg extension & \\
\hline & Seated marching on physioball & \\
\hline & Crossover crunch & \\
\hline \multirow{6}{*}{3} & Dead bug & 20 reps \\
\hline & Supine bridge on physioball & Hold $20 \mathrm{~s}$ \\
\hline & Supine bridge on physioball with shoulder flexion & 20 reps \\
\hline & Prone bridge on physioball & Hold $20 \mathrm{~s}$ \\
\hline & Cobra extension on physioball & Hold $20 \mathrm{~s}$ \\
\hline & Superman & Hold $2 \mathrm{~s} / 20$ reps \\
\hline \multirow{6}{*}{4} & Pelvic bridge alternating knee extension with physioball & 20 reps \\
\hline & Medicine-ball floor twist & 20 reps \\
\hline & Pelvic bridge with shoulder flexion on physioball & 20 reps \\
\hline & Curl-up on physioball & 20 reps \\
\hline & Pelvic bridge alternating knee extension and shoulder flexion & 20 reps \\
\hline & Superman on physioball & Hold $2 \mathrm{~s} / 20$ reps \\
\hline \multirow{4}{*}{5} & Lunge with medicine-ball twist & 20 reps \\
\hline & Abdominal flexion on physioball with medicine ball & 20 reps \\
\hline & Abdominal rollout & 20 reps \\
\hline & Ball bridge with alternate knee extension & Hold $2 \mathrm{~s} / 20$ reps \\
\hline \multirow{5}{*}{6} & Physioball lunge & 10 reps on each leg \\
\hline & Theraband-resisted march & 10 reps on each side \\
\hline & Iron cross on physioball & Total 20 reps alternating sides \\
\hline & Side bridge with shoulder abduction & 15 reps each side \\
\hline & Physioball alternate superman & Total of 20 reps \\
\hline
\end{tabular}




\section{STATISTICAL ANALYSES}

Demographic characteristics of the research sample are reported in Table 2. The information on the type and degree of vision impairment is also reported in Table 3. The data obtained from MANOVA were used to determine the interventional effect of core stability training on postural control, risk of falling, and function. Data analysis was performed in SPSS v.22 at the significance level of $95 \%$ and the alpha smaller or equal to 0.05 . The effect size (Hedge's G) was also calculated and interpreted by default between the group effect size and was classified into low (smaller than 0.4), medium (0.41-0.7), and high (larger than 0.71) effect size.

Table 2. Individual characteristics of the two groups*

\begin{tabular}{ccccc} 
Group & Number $(\mathrm{N})$ & Height $(\mathrm{cm})$ & Weight $(\mathrm{kg})$ & Age $(\mathrm{y})$ \\
\hline Experimental & 16 & $174.62 \pm 4.99$ & $75.73 \pm 9.05$ & $23.03 \pm 3.02$ \\
Control & 16 & $173.68 \pm 4.65$ & $73.43 \pm 6.39$ & $22.50 \pm 2.80$ \\
\hline
\end{tabular}

Table 3. Characteristics of the type and degree of blindness

\begin{tabular}{ccccc} 
& \multicolumn{2}{c}{ Type of blindness } & \multicolumn{2}{c}{ Degree of blindness } \\
\cline { 2 - 5 } Group & Congenital & Adventitious & Absolute Blind & Poor Blindness \\
\hline Number & 7 & 25 & 24 & 8 \\
Percentage & $21.9 \%$ & $78.1 \%$ & $75 \%$ & $25 \%$ \\
\hline
\end{tabular}

\section{RESULTS}

According to the results of the Shapiro-Wilk test, the distribution of data was normal in both groups. At the beginning of the study, based on independent t test, there was no significant difference between the two groups in terms of any variable $(p>0.05)$. Core stability training was significantly improved compared to the control group in all the variables $(p<0.05)$. Higher effect size and confidence interval of $95 \%$ were listed for all the variables. After the training intervention, significant improvement was found in function, postural control, and risk of falling variables compared to the control group $(p<0.05)$. All the research variables showed greater effect size with a confidence interval of $95 \%$ and exceeded zero (Table 4 ).

Table 4. Mean, standard deviation, and effect size of research variables ${ }^{+}$

\begin{tabular}{|c|c|c|c|c|c|c|}
\hline \multirow{2}{*}{\multicolumn{2}{|c|}{ Variables }} & \multicolumn{2}{|c|}{ Experimental Group } & \multicolumn{2}{|c|}{ Control Group } & \multirow{2}{*}{ Effect size } \\
\hline & & Pre Test & Post Test & Pre Test & Post Test & \\
\hline \multirow{3}{*}{$\begin{array}{l}\text { Postural } \\
\text { control *†‡ }\end{array}$} & $\begin{array}{l}\text { Berg balance } \\
\text { scale }\end{array}$ & $39.93 \pm 1.84$ & $49.43 \pm 3.70$ & $38.93 \pm 2.48$ & $39.81 \pm 2.53$ & $\begin{array}{c}1.37 \\
(0.60-2.14)\end{array}$ \\
\hline & $\begin{array}{l}\text { Stork stand } \\
\text { balance test }\end{array}$ & $6.51 \pm 1.10$ & $16.80 \pm 7.79$ & $6.65 \pm 0.97$ & $6.74 \pm 1.01$ & $\begin{array}{c}0.97 \\
(0.23-1.7)\end{array}$ \\
\hline & $\begin{array}{l}\text { tandem } \\
\text { walking test }\end{array}$ & $7.18 \pm 1.32$ & $12.12 \pm 1.14$ & $7.06 \pm 1.06$ & $8.00 \pm 1.03$ & $\begin{array}{c}1.36 \\
(0.59-2.13)\end{array}$ \\
\hline $\begin{array}{l}\text { Risk of } \\
\text { falling *十‡ }\end{array}$ & $\begin{array}{l}\text { Timed Get } \\
\text { up \& Go }\end{array}$ & $11.84 \pm 1.05$ & $7.10 \pm 1.07$ & $11.65 \pm 0.79$ & $11.10 \pm 0.67$ & $\begin{array}{c}-0.9 \\
(-1.63-0.18)\end{array}$ \\
\hline $\begin{array}{l}\text { Movement } \\
\text { function *†‡ }\end{array}$ & Tinetti tests & $14.68 \pm 1.44$ & $21.31 \pm 2.38$ & $14.68 \pm 1.40$ & $15.00 \pm 1.26$ & $\begin{array}{c}1.22 \\
(0.46-1.97)\end{array}$ \\
\hline
\end{tabular}

+ Values are presented as mean \pm SD.

* Indicates a significant change in the experimental group relative to the control group $(P<0.05)$

$\dagger$ Indicates a significant difference between the pre- and post-test collapsed means $(P<0.05)$.

$\ddagger$ Indicates a significant difference between the experimental and control group collapsed means $(P<0.05)$. 


\section{DISCUSSION}

Motor development of children is based on the growth of their fundamental motor skills, and different movement experiences lead to the development of fundamental motor skills and increase environmental awareness in children. This is more important among blind people, because they have more motor limitations. Therefore, the main purpose of this research was to examine the effect of a 6-week course of core stability training on postural control, risk of falling, and function of blind people. In the blind people, due to the lack of vision, the total amount of motor information and proper patterns in the central nervous system is decreased, which affects the balance function and leads to poorer balance of blind people than the seeing people at the same age [27]. The results showed there was no significant difference between experimental and control groups in terms of postural control tests, risk of falling, and function in pre-test. However, in the post-test, the experimental group had a better function in the above-mentioned factors than the control group.

There are several reports on the effect of training plan on the balance of visually impaired people and whether the balance defect in such people is improved through training or not. However, no research has been conducted on the effect of core stability training on function, risk of falling, and postural control of the blind people. In a study by Wiszomirska et al. [28] on evaluation of vestibular training plan on postural stability of people with visual impairment, it was concluded that training can improve the postural control and balance of blind people. This research consisted of 70 people with the mean age of 19.5 years old (28 participants with visual impairment and 42 healthy people) who used vestibular training for three months (twelve weeks) twice a week. Level 8 was used to evaluate the dynamic balance and the static level of Biodex Balance System was employed for static balance before and after the training intervention. Based on the results, a significant difference was observed in dynamic balance for women and in static balance for men between the experimental and control groups (vestibular training; 1.02 vas core stability training; 1.37). The cause of this improved balance in these individuals can be head and body movements to stimulate the vestibular system of the blind people [28]. Di Cagno et al. [24] investigated the acute effect of whole body vibration on postural control of 12 congenitally blind people as the experimental group and 12 healthy people as the control group. The extent of the centre of pressure displacement in the baseline was assessed immediately after the whole body vibration. The whole body vibration lasted for five 1-min sets. The results showed that the acute whole body vibration had an effect on postural control of blind people, so that no defect was observed in static balance after body vibration [24] and centre of pressure of the blind people had less displacement than the time before the vibration (whole body vibration training 0.6 vas core stability training; 1.36 ;). Hackney et al. [29] examined the effect of tango and fall proof training on 32 blind people aged 51-95 years old. The results showed that the balance function, mobility, and quality of life significantly improved after 12 weeks of 90-min training sessions and both methods reduced the risk of falling in blind people [29]. However, in comparison with core stability training used in this research, the effect size of training was lower $(0.9>0.26)$. Mavrovouniotis et al. [30] examined the effect of a course of combined exercises of Greek dances and Pilates on blind children. The results of their research showed a significant effect on three cases of static balance evaluation and four cases of dynamic balance evaluation in the experimental group. Hessari et al. [31] measured the effect 
of 8 weeks of core stability training on balance of students with hearing impairment. Static balance was measured through an assessment of balance errors, and dynamic balance was measured through a star balance test. The results showed that a significant increase was observed in static and dynamic balance following 8 weeks' core stability training in the experimental group. It also showed that the group was examined in four directions: interior, posterior, inner posterior, and outer posterior. After completing the training protocol, the tests were re-evaluated, and the results showed that the functional, agility, and balance factors were improved [31]. Kushiro examined the effect of core stability training on trunk function, standing balance, and mobility in stroke patients. The research samples consisted of 32 participants in two groups of experimental and control (16 participants per group) and there was a significant difference in 4 experimental groups after 4 weeks. But the results of this research were in contrast to the research by Clary et al. [32], who reported that 13 weeks of core stability training had no effect on the balance of the elderly women and were also inconsistent with Piegaro [33], who reported that core stability training was less effective than the balance exercises on the balance of 39 participants who were assigned to four training groups and trained for 4 weeks. The nature of the core stability training was similar in the studies, but the inconsistence between the results of this research and the results of the above studies could be due to the differences in variables, such as age assessment method and activity level. Another reason is that in the above studies, mostly the healthy people were examined who had less balance disorder.

Training protocols for strengthening the core muscles like the protocol presented in this research can be performed at home. They are designed to strengthen key body muscles at abdominal area and lower back and increase the muscle strength and functional access at all levels of movement. Therefore, without designing a certain program to strengthen the core muscles, any standard training program used to strengthen other muscles may not be effective for increasing functional access. Despite the usefulness of other training program to keep the daily functional activity, examples such as the program provided by the researcher are more effective (given the effect size referred above). In the blind people, due to the lack of vision, the total amount of motor information storage and proper motor patterns in the central nervous system is decreased, which affects the balance function of the person and leads to poorer balance of blind people than the seeing people at the same age [27]. Postural control and balance can be improved via training and proper activity with coordination of activities that involve power [34]. Core stability training improves strength, endurance, and nerve control in this area, interior spinal cord control, interior abdominal pressure control, and muscle control of trunk motion and affect the body's ability to keep balance in various dynamic movements [35]. Regarding the effect of playing with Swiss balls on dynamic balance, it seems that the improved postural control while playing with the ball is because of placement on the ball and modification of body weight from muscles and joints, an individual can perform a wide range of movements without the risk of injury and falling in a recreational manner. The balance disturbance forces that are created while being on the ball can provide a proper activity to challenge the systems involved in balance. The combination, repetition, and speed of movements also improve the flexibility and reaction time; these factors play a major role in maintaining balance [36]. Once it can be deduced that participating in core stability training leads to improved balance and postural control and core strength, it cannot be concluded that no change is experienced in muscle activation patterns. Although further research is required on these exercises, the results of research suggest 
that core stability training can be beneficial for improving balance via muscle strengthening, which is often related to spinal cord and hip control. Besides, the improved postural control in core stability training is due to the point that this type of training improves the musculoskeletal system, increases the body strength, reduces the centre of pressure movement outside the base of support, and increases the length of standing on one leg [37]. In fact, the core stability training strengthens the muscles in this area and, consequently, improves the postural control. Anatomically, the core area of body is where the centre of pressure is located and is considered as the point of support [37]. Hence, it seems that the core stability training followed by strengthening the muscles in this area reduces the centre of pressure displacement, sway, and, therefore, risk of falling. Accordingly, based on the benefits of both balance and stabilizing training for the blind people, the combined balance and core stability plan where the central stabilizing exercises are initially performed will be a more useful plan for blind people. Given the increasing development of disability exercises, especially for the blind, who are considered as an important part of the active society, and also the postural control that plays an important role in the daily activities of these people, further studies are required for improving quality of life of these people.

One of the limitations in this research was lack of control of the subjects' psychological state, which can somehow affect the research results; same-gender samples, lack of access to samples, and small sample size are other limitations. It was necessary for the participants to perform tests with high precision and concentration; but there was a possibility of lack of attention by them in performing the tests, which was not controllable by the examiner. Another limitation in this research could be having one type of training program, which was not compared with other exercises; this can create another subject of study for other researchers to compare core stability training with other exercises.

\section{CONCLUSIONS}

Given the results of the present study, it can be concluded that core stability training leads to improved balance at static and dynamic levels, function, and reduced risk of falling in blind people. Along with other plans, these exercises can be used in order to rehabilitate and improve the function. However, core stability training and its effects on physical fitness factors, including balance in blind people, require further research.

\section{ACKNOWLEDGEMENTS}

We would like to appreciate the cooperation of the blind students of University of Tehran.

\section{REFERENCES}

[1] Salomão SR, Mitsuhiro MR, Belfort Jr R. Visual impairment and blindness: an overview of prevalence and causes in Brazil. Anais da Academia Brasileira de Ciências. 2009;81(3):539-49. https://doi. org/10.1590/S0001-37652009000300017

[2] Ramezani A, Pardis M, Rafati N, et al. Causes of visual impairment among patients referred to a visual rehabilitation clinic in Iran. Korean Journal of Ophthalmology. 2012;26(2):80-3. https://doi. org/10.3341/kjo.2012.26.2.80

[3] Bourne RR, Flaxman SR, Braithwaite T, et al. Magnitude, temporal trends, and projections of the global prevalence of blindness and distance and near vision impairment: A systematic review and meta-analysis. The Lancet Global Health. 2017;5(9):e888-e97.

[4] Fortin M, Voss P, Lassonde M, Lepore F. Sensory loss and brain reorganization. Med Sci. 2007;23(11):917-22. https://doi.org/10.1051/medsci/20072311917 
[5] Winter DA, Patla AE, Prince F, Ishac M, Gielo-Perczak K. Stiffness control of balance in quiet standing. J Neurophysiol. 1998;80(3):1211-21. https://doi.org/10.1152/jn.1998.80.3.1211

[6] Parreira RB, Grecco LAC, Oliveira CS. Postural control in blind individuals: A systematic review. Gait \& Posture. 2017;57:161-7. https://doi.org/10.1016/j.gaitpost.2017.06.008

[7] Mills JD, Taunton JE, Mills WA. The effect of a 10-week training regimen on lumbo-pelvic stability and athletic performance in female athletes: a randomized-controlled trial. Phys Therap Sport. 2005;6(2):60-6. https://doi.org/10.1016/j.ptsp.2005.02.006

[8] Hadadnezhad M, Rajabi R, Alizadeh MH, Letafatkar A. Does core stability predispose female athletes to lower extremity injuries? J Res Rehabil Sci. 2010;6(2):89-98.

[9] Bagherian S, Ghasempoor K, Rahnama N, Wikstrom EA. The effect of core stability training on functional movement patterns in college athletes. J Sport Rehabil. 2019;28(5):444-9. https://doi. org/10.1123/jsr.2017-0107

[10] Amiri B, Sahebozamani M, Sedighi B. The effects of 10-week core stability training on balance in women with multiple sclerosis according to Expanded Disability Status Scale: A single-blinded randomized controlled trial. Eur J Phys Rehabil Med. 2019;55(2):199-208. https://doi.org/10.23736/ S1973-9087.18.04778-0

[11] Ozsoy G, Ilcin N, Ozsoy I, et al. The effects of myofascial release technique combined with core stabilization exercise in elderly with non-specific low back pain: A randomized controlled, single-blind study. Clinl Intervent Aging. 2019;14:1729. https://doi.org/10.2147/CIA.S223905

[12] Park J-M, Hyun G-S, Jee Y-S. Effects of Pilates core stability exercises on the balance abilities of archers. J Exercise Rehabil. 2016;12(6):553. https://doi.org/10.12965/jer.1632836.418

[13] Akuthota V, Ferreiro A, Moore T, Fredericson M. Core stability exercise principles. Curr Sport Med Reps. 2008;7(1):39-44. https://doi.org/10.1097/01.CSMR.0000308663.13278.69

[14] Iacono AD, Martone D, Alfieri A, Ayalon M, Buono P. Core Stability Training Program (CSTP) effects on static and dynamic balance abilities. Gazzetta Medica Italiana Archivio per le Scienze Mediche. 2014;173(4):197-206.

[15] Granacher U, Schellbach J, Klein K, Prieske O, Baeyens J-P, Muehlbauer T. Effects of core strength training using stable versus unstable surfaces on physical fitness in adolescents: a randomized controlled trial. BMC Sports Science, Medicine and Rehabilitation. 2014;6(1):40. https://doi. org/10.1186/2052-1847-6-40

[16] Hassan IHI. The effect of core stability training on dynamic balance and smash stroke performance in badminton players. Int J Sport Sci Phys Educ. 2017;2(3):44-52. https://doi.org/10.11648/j. ijsspe.20170203.12

[17] Cohen J. Statistical power analysis for the behavioral sciences. Routledge; 2013. https://doi. org/10.4324/9780203771587

[18] Gaerlan MG. The role of visual, vestibular, and somatosensory systems in postural balance. UNLV Theses, Dissertations, Professional Papers, and Capstones, no. 357; 2010.

[19] Ebrahimi Takamjani E, Noorbakhsh M, Basiri S. Assessing the influence of sensory information on controling standing balance in different age groups. Razi J Med Sci. 2000;7(21):171-5.

[20] Aydoğ E, Aydoğ S, Cakci A, Doral M. Dynamic postural stability in blind athletes using the biodex stability system. Int J Sport Med. 2006;27(05):415-8. https://doi.org/10.1055/s-2005-865777

[21] Wood-Dauphinee S, Berg K, Bravo G, Williams J. The Balance Scale: responsiveness to clinically meaningful changes. Can J Rehabil. 1996;10:35-50.

[22] Bogle Thorbahn LD, Newton RA. Use of the Berg Balance Test to predict falls in elderly persons. Phys Therap. 1996;76(6):576-83. https://doi.org/10.1093/ptj/76.6.576

[23] Salar S, Daneshmandi H. Relationship between lumbar-pelvic function and static and dynamic balance in children with autism spectrum disorders. J Rehab Med. 2017; 6(2):168-179.

[24] di Cagno A, Giombini A, Iuliano E, et al. Acute effect of whole body vibration on postural control in congenitally blind subjects: a preliminary evidence. Disabil Rehabil. 2018;40(22):2632-6. https://doi. org/10.1080/09638288.2017.1353650

[25] Tyson SF, DeSouza LH. Reliability and validity of functional balance tests post stroke. Clin Rehabil. 2004;18(8):916-23. https://doi.org/10.1191/0269215504cr821oa

[26] Jeffreys I. Developing a progressive core stability program. Strength Condition J. 2002;24(5):65-6. https://doi.org/10.1519/00126548-200210000-00017

[27] Ray CT, Horvat M, Croce R, Mason RC, Wolf SL. The impact of vision loss on postural stability and balance strategies in individuals with profound vision loss. Gait \& Posture. 2008;28(1):58-61. https:// doi.org/10.1016/j.gaitpost.2007.09.010

[28] Wiszomirska I, Kaczmarczyk K, Błażkiewicz M, Wit A. The impact of a vestibular-stimulating exercise regime on postural stability in people with visual impairment. BioMed Res Int. 25 Oct 2015;2015:136969. https://doi.org/10.1155/2015/136969

[29] Hackney ME, Hall CD, Echt KV, Wolf SL. Multimodal exercise benefits mobility in older adults with visual impairment: a preliminary study. J Aging Phys Act. 2015;23(4):630-9. https://doi.org/10.1123/ japa.2014-0008

[30] Mavrovouniotis FI, Papaioannou CS, Argiriadou EA, et al. The effect of a combined training program with Greek dances and Pilates on the balance of blind children. J Phys Educ Sport. 2013;13(1):91.

[31] Hessari FF, Norasteh AA, Daneshmandi H, Ortakand S. The effect of 8 weeks core stabilization training program on balance in deaf students. Medicina Sportiva. 2011;15(2):56-61. https://doi. org/10.2478/v10036-011-0010-4

[32] Clary S, Barnes C, Bemben D, Knehans A, Bemben M. Effects of ballets, step aerobics, and walking on balance in women aged 50-75 years. J Sport Sci Med. 2006;5(3):390. 
[33] Piegaro A. The comparative effects of four-week core stabilization and balance-training programs on semidynamic and dynamic balance. Master's thesis. Morgantow; 2004.

[34] Smail KM, Horvat M. Effects of balance training on individuals with mental retardation. Clin Kinesiology (Online). 2005;59(3):43.

[35] McCaskey A. The effects of core stability training on star excursion balance test and global core muscular endurance. University of Toledo; 2011.

[36] Douris P, Southard V, Varga C, Schauss W, Gennaro C, Reiss A. The effect of land and aquatic exercise on balance scores in older adults. J Geriatric Phys Therap. 2003;26(1):3-6. https://doi. org/10.1519/00139143-200304000-00001

[37] Launer L, Berger K, Breteler M, et al. Prevalence of Parkinson's disease in Europe: A collaborative study of population-based cohorts. Neurologic Dise ases in the Elderly Research Group. Neurology. 2000;54(11 Suppl 5):S21-3. 